AperTO - Archivio Istituzionale Open Access dell'Università di Torino

\title{
Stability and Change in Youths' Political Interest
}

\section{This is the author's manuscript}

Original Citation:

Availability:

This version is available http://hdl.handle.net/2318/1666612

since 2018-04-16T10:46:28Z

Published version:

DOI:10.1007/s11205-016-1302-9

Terms of use:

Open Access

Anyone can freely access the full text of works made available as "Open Access". Works made available under a Creative Commons license can be used according to the terms and conditions of said license. Use of all other works requires consent of the right holder (author or publisher) if not exempted from copyright protection by the applicable law. 
Running head: STABILITY AND CHANGE IN YOUTHS’ POLITICAL INTEREST

\title{
Stability and change in youths' political interest
}

\author{
Silvia Russo (corresponding author) \\ Youth \& Society \\ Örebro University \\ Fakultetsgatan 1 \\ 70182 Örebro, Sweden \\ Tel. +46(0)19303469 \\ Email: silvia.russo@oru.se \\ Håkan Stattin \\ Youth \& Society \\ Örebro University
}

\section{Acknowledgments}

This study was made possible by access to data from the Political Socialization Program, a longitudinal research program at YeS (Youth \& Society) at Örebro University, Sweden (Amnå, Ekström, Kerr \& Stattin, 2009). Responsible for the planning, implementation, and financing of the collection of data were professors Erik Amnå, Mats Ekström, Margaret Kerr and Håkan Stattin. The data collection was supported by grants from Riksbankens Jubileumsfond. The study has been approved by the regional Ethical Committee at Uppsala, Sweden. 


\title{
Stability and change in youths' political interest
}

\begin{abstract}
Political interest is a key for the survival and development of democracies. Therefore, it is important to establish when political interest develops. We examined changes in political interest - when and in which directions - among youths between 13 and 28 years of age. We followed five age groups of Swedish youths over two years, with a total of 2,621 participants. Analysis of stability coefficients supported the idea that political interest becomes more stable with age. From their early twenties, youths' political interest was found to be as stable as has been earlier reported for adults. Among adolescents, the lowest stability rate was observed in the youngest cohort (ages 13 to 15). The results also showed that, when taking the increase in political interest into account, the proportion of youths losing their interest in politics corresponded to the proportion of youths gaining interest over time. On the whole, this study brings new insights on the development of political interest over time. It provides empirical evidence on when political interest is most susceptible to change and on how it is likely to change. Implications for research and intervention are discussed.
\end{abstract}

Keywords: political interest; youths; attitudinal stability; longitudinal data. 
Politically interested citizens are attentive to political information and have the motivation and skills to learn from news sources (Strömbäck and Shehata 2010). Thus, they are politically knowledgeable and sophisticated (Delli Carpini and Keeter 1996; Eveland and Scheufele 2000). They initiate and enjoy political discussions in different contexts and with different partners (Bennett et al. 2000), and believe that their contributions can make a difference to society (Craig et al. 1990). They are committed not only to vote, but also to engage in a variety of offline and online political activities (e.g., Best and Krueger 2005; Verba et al. 1995). Even though political interest may interact with other factors, it stands out as the most important predictor of dozens of democratic outcomes (Shani 2009). For instance, Brady et al. (1995) report that political interest is the single most important determinant of political participation, with standardized regression coefficients over .45 after controlling for other political resources. Interest in political matters, defined as the degree to which politics arouses citizens' curiosity (van Deth 1989), has been considered the motivational dimension of politics (Silvia 2008), and has to be differentiated from the behavioral (political involvement) and cognitive (political sophistication) dimensions. As such, political interest typically precedes any form of political action (Hooghe and Dejaeghere 2007). In sum, people interested in politics are important for the survival and development of democracies.

Contemporary democracies have two main challenges to face. The first, obviously enough, is that not all people think that politics is interesting. About every other person perceives political issues as tedious. In the last available European Social Survey (ESS Round 6 2012), only $44.6 \%$ of respondents reported themselves to be quite or very interested in politics; similarly, in the United States, the proportion of citizens who were somewhat or very interested in politics in 2013 was $40.7 \%$ (ANES data, 2012, web survey). The second is that it is unlikely that uninterested people will become interested in the future. Prior (2010) recently showed that, already in their twenties, citizens show an extremely stable level of 
political interest. Thus, to understand when political interest starts to stabilize, we have to examine the development of political interest before that age. In this study we address the questions - Does political interest change over time? When does it change? And how does it change? - by analyzing longitudinal survey data collected from Swedish youths in the age range 13 to 28 , i.e., covering both adolescence and early adulthood.

\section{Stability and Change in Political Interest}

Two opposite perspectives have dominated research on stability and change in political attitudes so far. The lifelong openness hypothesis holds that people are open to change throughout their lives and show attitudinal flexibility in response to changing life experiences (Sears 1983). According to this idea, political interest should show fluctuations over time. To the contrary, the lifelong persistence hypothesis holds that political attitudes are resistant to change. On this view, what is learned early in life is likely to endure and to be stable over time (Sears 1983). In between these two main perspectives, a number of propositions on the relationship between age and stability/change in political attitudes have been advanced. For example, the impressionable years hypothesis maintains that political attitudes are susceptible to change during late adolescence and young adulthood, but that, after this life stage, attitudes are highly stable (Krosnick and Alwin 1989). Another similar possibility is that attitudinal change gradually decreases with age, which is a prediction of the increasing persistence hypothesis (Alwin 1994). However, empirical tests of these latter hypotheses are scarce.

Kinder and Sears (1985) reviewed all the longitudinal, cohort, and experimental studies on stability and change in political attitudes available up to the mid-eighties, and concluded that the best way to examine the development of political attitudes over time is to take into account "continuing socialization and occasional re-socialization through adolescence and into adulthood and diminishing but still noticeable levels of change thereafter" (p. 724). Early research on stability and change in political interest over time supported this view, and hence 
the lifelong openness hypothesis, by showing that political interest is less stable than other political attitudes (Jennings and Markus 1984), and also that political interest tends to increase with age (Glenn and Grimes 1968). However, Prior's (2010) analysis of the stability of political interest challenged these first findings. He analyzed data from eleven panel surveys conducted in Europe and the United States, and found that political interest had an exceptionally high absolute, individual-level stability in both the short and the long run. Prior showed that political interest was already highly stable among people in their twenties; moreover, he noted that the patterns were not substantially different when considering only a subsample of respondents below the age of 22 years, and advocated new studies focusing on the development of political interest in adolescence and childhood.

A few contributions in the area of developmental political psychology have focused on political understanding during childhood and the early years of adolescence. Children start to develop political orientations and to hear about political figures already at the beginning of primary school (Connell 1971; van Deth et al. 2011). However, it is first between the ages of 10 and 12 that the full emergence of a "naïve political theory" takes place (Berti 2005). At this time, children can distinguish between central and local political offices, develop a standard idea of political parties and elections, and are aware that laws are made by parliament (Berti 2005). Even if none of these contributions has focused on political interest, they show that early adolescents have a fairly good understanding of what politics is. Therefore, we can assume that they might display different levels of interest in political matters already at this age.

Nonetheless, longitudinal studies addressing stability and change in political interest during adolescence are surprisingly scarce. One reason for this is that the majority of studies have relied on available panel datasets, typically collected by national survey institutions (e.g., the American National Election Studies), which mostly include citizens over 18. For 
example, Shani (2009) examined the relative and absolute stability of political interest using panel data from the Youth-Parent Socialization Study (Jennings and Niemi 1974; 1981). She compared the political interest of youths at 18 and 26 years of age and found high stability, with a correlation coefficient of .87 after correcting for measurement error; $49.8 \%$ of respondents reported exactly the same level of political interest (on a 4-point scale) in the first and second waves of the survey. She also analyzed the degree of stability in political interest of the same respondents at 35 and 50 years and, finding that political interest tends to stabilize as age increases, concluded that "there is high degree of continuity" (p. 53). In contrast, Neundorf, Smets, and García-Albacete (2013) - analyzing German panel data collected from a sample of youths aged 17 to 35 - observed a positive linear trend in political interest from 17 to 25 years, after which political interest seemed to stabilize.

On the whole, previous research clearly indicates that political interest is highly stable in adulthood, and that we need to focus on adolescents to observe more substantial changes (Prior 2010). However, studies focusing on youths' development of political interest have had mixed results regarding whether political interest is susceptible to change during late adolescence and young adulthood: Some authors have observed changes (Neundorf et al. 2013), whereas others have reported high stability (Prior 2010; Shani 2009). More importantly, none of these studies has addressed the stability of political interest during the early stage of adolescence.

\section{The Direction of Change in Political Interest}

Research on the development of political interest (e.g., Neundorf et al. 2013) largely embraces the assumption that adolescents and older youths become more interested in politics and public affairs as they grow older. This assumption is in line with two interpretations of the link between age and political interest. On the one hand, the political life cycle model holds that young people are disinterested in politics because they are 
distracted by their struggles for careers, jobs, partners, and so on; they are seen either as busy preparing for their future or as attracted by other activities that absorb their leisure time, e.g., sports, partying (Glenn and Grimes 1968). On the other hand, the psychological aging perspective suggests that youths are disinterested in politics because they do not regard politics as relevant to their lives (van Deth 1989). Both lines of reasoning imply that a rise in political interest should characterize the early adulthood years since youths assume adult roles at this time. Neundorf and colleagues (2013) recently tested this idea and reported an overall positive linear relationship between age (17 to 25$)$ and political interest. They found that, with every year of aging, youths' political interest increased by 0.02 points on a 1 to 4 scale, which is a fairly small rate of increase. They also reported that - when change in political interest is modeled by a linear growth function - the variance of the slope was statistically significant, indicating that there is individual variation in the development of political interest among youths. In other words, their study shows that, in general, interest slightly increases with age but that, at individual level, youths may display different developmental trajectories.

The general conclusion that political interest increases from late adolescence to young adulthood is contestable for two main reasons. First, we do not know the extent to which interest in political matters changes at earlier ages. Given that some political attitudes are formed during the early stages of adolescence (e.g., Hooghe and Wilkenfeld 2008), we might expect to observe substantial increases in political interest even before late adolescence. Second, although researchers generally do not deny the possibility that youths can lose their interest over time, they have typically overlooked that possibility. Indeed, the normative assumption of an increase in political interest with age has influenced the analytical strategies applied to the study of its change (e.g., the use of aggregate mean levels and linear growth models). Thereby, researchers' attention has been diverted from the opposite possibility, 
namely that a substantial proportion of youths are likely to lose their interest in politics. That is, most previous studies have analyzed group trends but have left individual-level change unexplored. In general, “if, for a valid description and explanation of behavior and development, it is important to take into account that results can differ across individuals, then aggregate level statements are in danger of being at least incomplete" (von Eye et al. 2006, p. 982).

The main theoretical models of the development of interest support the idea that individual interest is susceptible to either an increase or a decrease. According to these models (cf. Hidi and Renninger 2006; Krapp 2007), interest is a relational concept, and describes a more or less durable specific relationship between a person and an object in his/her life-space. The development of interest is conceived as a process starting with a transitional situational interest, a state close to the experience of curiosity triggered by external stimuli, which eventually develops into a more stable individual interest. The process of interest internalization is driven by many factors, ranging from cognitive evaluations, based on personal values and goals, to affective components such as emotionrelated experiences triggered by engagement with the object of interest (Krapp 2007). Developmental models of interest suggest that initial situational interests have to encounter many facilitating conditions to be fully developed and internalized into an enduring individual interest, a stable predisposition. When social conditions (such as support from others) are not favorable, individual level of interest might fall back to that of a previous phase or disappear altogether (Hidi and Renninger 2006). In sum, according to these models, increase and decline in youths' political interest over time are equally likely outcomes.

To analyze these individual-level changes, we need to attend to both increases and decreases over time in political interest. To the best of our knowledge, only one published study has provided some information about the direction of change in political interest among 
adolescents at an individual level. Dostie-Goulet (2009) conducted a study to assess the impact of social networks on the development of political interest and, for this purpose, collected longitudinal data on a group of 14-15 year-old high school students three times at one-year intervals. She reported that about one-third of respondents showed an increase (defined as a change of at least 1 point on a 10-point scale) in political interest one year later, about one-fifth showed a decrease, and half remained stable. However, she did not provide in-depth information on the dynamics of change, and many questions still remain unanswered. For example, is the proportion of adolescents who show an increase in political interest different from the proportion of those who show a decrease? Are these trends the same for adolescents and young adults?

\section{The Present Study}

The literature so far has shown that, if we want to study change in political interest, we need to focus on adolescents (Prior 2010) and compare them with older age cohorts. Nonetheless, a systematic analysis of the development of political interest among adolescents and young adults has not yet been carried out. In the present study, we present such an analysis, and address the questions of when and how political interest changes over time among adolescents and young adults.

Based on previous research on the stability of political interest over time, and in line with the impressionable years hypothesis (Krosnick and Alwin 1989), we expected to observe more change in political interest during the high-school years (from age 13 to 18) than later on in life; we also expected political interest to show high stability among youths in their twenties (Prior, 2010). Concerning developmental trends, we predicted a general trend of increase in political interest over time during adolescence (Neundorf et al. 2013). Moreover, given that developmental theories of interest suggest that an emerging individual interest may become a well-developed interest (Hidi and Renninger 2006), but may decrease if not 
supported, we examined the direction of change in political interest at individual level to understand how many uninterested youths become interested over time and vice-versa.

\section{Method}

\section{Data}

We relied on longitudinal survey data gained in Sweden on five cohorts of adolescents and young adults (aged 13, 16, 20, 22, and 26 at the time of the first survey) living in Örebro, a city of about 130,000 inhabitants, which is similar to the country as a whole with regard to its immigration rate, income level, and unemployment rate (www.scb.se, www.kolada.se). Participants were surveyed twice at a two-year interval (at times $\mathrm{T}_{1}$ and $\mathrm{T}_{2}$ ). In total, 2,621youths participated in both waves. All data were collected between 2010 and 2013.

Adolescents in the younger cohorts (13- and 16-year-olds) completed the surveys during regular school hours in sessions with trained test administrators. Parents were informed of the study ahead of time and could say no to their children's participation by returning a note in a pre-paid envelope. A contribution of $110 €$ was made to class funds. Respondents to the first wave were 904 in the 13 -year-old group (52.4\% female) and 892 in the 16-year-old group ( $49.8 \%$ female); respondents to the second wave were 843 in the 13 year-old group and 740 in the 16-year-old group. On the whole, 68913 -year-olds and 592 16year-olds participated in both waves; response rates ranged between $80.79 \%$ and $94.17 \%$, with an average response rate of $87.03 \%$ for these age cohorts. The samples were similar to the Swedish national population of the corresponding age in terms of gender distribution and nationality (proportion of adolescents born outside the country).

For the older cohorts $(20,22$, and 26 year-olds), the target samples $(N=1000$ in each age group) were randomly extracted from the total populations of the corresponding age groups living in Örebro. For both waves, the questionnaire was mailed to the target samples, together with information about the study and a personalized link to the online version of the 
questionnaire. Participants received a gift card of approximately $28 €$ for their participation. Respondents to the first wave were 605 (62.4\% female), 539 (64.5\% female), and 606 (56.7\% female), while respondents to the second wave were 600, 560, and 596 in the 20-, 22-, and 26-year-old groups respectively. On the whole, 465 20-year-old, 406 22-year-old, and 469 26-year-old participated in both surveys; response rates ranged between $57.38 \%$ and $61.73 \%$, with an average response rate of $59.87 \%$ for these age cohorts. Compared with the national population, in our sample, girls were slightly overrepresented, and youths born outside Sweden slightly underrepresented.

Adolescents in the younger cohorts participated in an additional survey one year after the first wave. We did not use these data in the main analyses of this study because we could not make comparisons with similar information in older cohorts. However, we did use the data to describe the mean level of political interest (see Figure 1) and to estimate the measurement error variance for computing corrected correlations (see below).

\section{Measures and Attrition Analysis}

To assess political interest we relied on a single item: "How interested are you in politics?" Response options were as follows: 1 'totally uninterested', 2 'not interested', 3 'not especially interested', 4 'fairly interested', 5 'very interested' (see, for example, the ANES 2008-9 Panel Study for the same item). This item has become the standard measure in the literature. When possible, scholars generally prefer to use this direct measure of interest over multiple indicators (e.g., the frequency of interpersonal discussion about political issues) that might mix up a measure of individual interest in politics with different motivations or goals. Indeed, the simple self-placement question has the benefit of avoiding "complications related to the distinction between interest and behavioral utterances or consequences of interest" (van Deth and Elff 2000, p. 33). 
We checked whether youths who participated in both waves differed from those who participated only in the first wave by comparing the mean levels of political interest in the two groups, for each cohort. No significant differences were found. We also ran a logistic regression analysis (participants with responses at both time points coded 1; those who participated only the first time coded 0$)$ with political interest, gender $(1=$ female $)$, and nationality $(1=$ born outside Sweden $)$ included as independent variables. Significant differences were found only for gender $(\mathrm{Wald}=9.07, p<.01)$. In general, low Nagelkerke $\mathrm{R}^{2}$ (.007) indicated that the differences between those who participated in both the assessments and those who responded only to the first one were not substantial.

\section{Analytical Strategy}

We analyzed the relative stability, i.e. the extent to which people change their interest relative to one another, of political interest over time through four measures of correlation: Kendall's tau-b and Spearman's rho rank correlations, Pearson's product moment correlation, and the same correlation with its value corrected for unreliability of measurement, following the procedure suggested by Achen (1975). The correction of correlations (disattenuated correlations) is a well-known statistical procedure used to correct parameter estimates for the attenuating effects of random error of measurement (Wiley and Wiley 1970). The procedure requires estimation of the amount of measurement error variance in the survey question, $\sigma_{\mathrm{e}}^{2}$ : This is possible when three assessments are available by applying Achen's (1975, p. 1222) formula. In the current study we estimated the error variance using the three assessments available for the $13\left(\sigma_{\mathrm{e}}^{2}=.30\right)$ and $16\left(\sigma_{\mathrm{e}}^{2}=.23\right)$ year-old cohorts. For the older cohorts, for which three waves of data were not available, we corrected the correlations using the estimated error variance for the 16 year-old cohort. Given that this might be an overestimation of the error variance in older cohorts, corrected correlations have to be interpreted with caution. 
Correlation coefficients can be problematic for estimation of absolute stability over time, i.e., the extent to which people report the same level of interest compared to their own previous level of interest. If there is a systematic change in a sample (between $T_{1}$ and $T_{2}$ ), this change will not be captured by a correlation coefficient. Stability coefficients remain the same if the response distribution is shifted upward or downward (Madsen 2004). To overcome this problem, we also report the percentages of youths who gave the same response both initially and two years later and the percentage of those who changed by no more than one response category.

To examine the direction of change in political interest we first looked at mean level differences between ages in our sample. Second, we used latent change models (LCMs; McArdle and Nesselroade 1994). Measures of political interest were included as manifest variables and served as indicators of two latent factors: By fixing all loadings at 1 , the latent intercept reflects the mean level of political interest at the first assessment, whereas the latent slope reflects the amount of linear change that occurred between the two time points. The main advantage of these models is that changes over time are represented as factors. Thus, it is possible to estimate the variances of the latent intercept and slope that represent the amount of inter-individual differences in mean levels of political interest at $\mathrm{T}_{1}$ and of change over time (Hertzog and Nesselroade 2003). We used this analysis as a starting point for understanding if there is individual variation around the general trend.

Finally, we examined the individual directions of changes - both increases and decreases - in political interest through the analysis of turnover tables and log-linear models. We tested whether the proportion of youths reporting an increase in political interest was the same as the proportion of youths losing interest over time (quasi-symmetry hypothesis, cf. Agresti 2013). The quasi-symmetry hypothesis concerns only the frequencies that are off the main diagonal, as the main diagonals contain frequencies of youths who did not change level 
of political interest over time. This hypothesis assumes that the cells above and below the main diagonal display the same distributions. Moreover, it does not assume marginal homogeneity; this means that the symmetry of the association between variables is estimated by using different parameters for row and column categories. We evaluated the distance between the observed distribution of political interest and the distribution entailed by the hypothesis through the overall goodness-of-fit statistic likelihood ratio $G^{2}$ (von Eye and Mun 2013). All the analyses were performed in SPSS 22, with the exception of the latent change models, which were constructed in Mplus 6.

\section{Results}

\section{Stability and Change in Political Interest}

We analyzed the correlations between political interest at $\mathrm{T}_{1}$ and $\mathrm{T}_{2}$, i.e., relative stability coefficients. Table 1 reports four measures of correlation for each cohort, as well as for the overall sample. The results clearly show a pattern of increasing stability in political interest across cohorts, regardless of the type of correlation. For example, the corrected correlation rose from .47 among 13 year-olds to .85 among 26 year-olds. The corrected correlation in the oldest cohort has a magnitude in line with that reported by Shani (2009) for the Youth-Parent Socialization Study. Between the ages of 18 and 26 she found a stability coefficient of .87 .

When taking into account the proportion of youths who moved by no more than one response (see bottom part of Table 2), $78 \%$ of the adolescents in the youngest cohort proved to have a stable political interest over time, but this proportion reached $95 \%$ in the oldest cohort. Also in this case, it is worth noting that the proportion of stable youths in our older cohort is in line with the results of Prior (2010) on the British Election Study panel, in which political interest was assessed using a 5-category response scale. He reported that the 
proportion of respondents who had moved by no more than one category two years after the first survey was over $90 \%$.

On the whole, regardless of which criterion is used to evaluate stability, the pattern in the results is clear: The greatest instability in political interest is observed between 13 and 15 years of age; between 16 and 18 political interest instability decreases; and from 20 years of age onwards the stability of interest in politics reaches the levels reported in previous studies of representative samples over 18. The only exception is that the correlation coefficients indicated that political interest in the 16 year-old group is already as stable as in the 20 yearold group (for example, Pearson's $r$ s among 16 and 20 year-olds are not statistically different, $z=-1.62, p=.11$ ), whereas the rates of youths giving the same response two years later indicated that the level of stability among 16 year-olds is significantly lower than that among 20 year-olds $(z=-3.39, p<.001)$. One reason for this discrepancy may be that, among 16 year-olds, there is systematic variation in interest that inflates the correlation coefficients but not the rates of adolescents providing the same response two years later. We examine this possibility in the following section.

\section{The Direction of Change in Political Interest}

So far we have addressed the questions of if and when political interest shows stability and change in different age cohorts. However, the analyses described above do not provide information about the direction of change in political interest. To address this issue we first described political interest as a function of age in the total sample. As shown in Figure 1, the young adolescents were, on average, less interested in politics than the older youths. As early as at age 13 , they showed a mean interest of 2.35 on a 1 to 5 scale, whereas the mean interest was 3.15 for the 28 year-old youths. There was a wider gap between 15 and 20 years, when the mean score for political interest increased from 2.47 to 3.07 (Cohen's $d=0.56$ ). By contrast, interest levels were substantially the same between 20 and 28 years of age (Cohen's 
$d=0.08$ ). At a descriptive level, our data are in line with previous empirical findings showing that, as adolescents grow older, they report higher levels of political interest (van Deth 1989).

Second, we used latent change models to analyze the direction of change within each age group. Table 2 summarizes the LCM parameter estimates (based on the Robust Maximum Likelihood estimator, MLR) for each cohort. The mean slope is positive and significant only in the younger cohorts, indicating that political interest showed a substantial increase over the two years in these cohorts. More important than mean changes are the significant variance estimates for all parameters, pointing to substantial inter-individual differences with regard to both initial levels of and rates of change in political interest. Taken as a whole, our results concerning the direction of change at group level indicate that there is an overall increase in political interest among adolescents aged 13 to 18 , and that the increase is greater between ages 16 and 18 than between earlier ages. By contrast, level of political interest does not change among youths aged 20 to 28 . However, these group trends do not capture all the individual variations in political interest.

To analyze the direction of political interest at individual level, we recoded our interest measure into a trichotomy for easier inspection: We created a group of youths characterized by low interest in politics (those who reported themselves to be totally disinterested or not interested in politics), a group with medium interest (those who were not especially interested), and a group with high political interest (those who were fairly or very interested). Turnover rates (and row percentages) for these recoded variables are reported in the upper part of Table 3. Also, we fitted a set of log-linear models to the data in Table 3: We tested the hypothesis that frequencies in symmetric positions around the main diagonal have a similar structure. More specifically, we tested whether - taking into account the general increase in political interest - there are comparable flows from low to high interest and from high to low interest over time. As reported in Table 3, the quasi-symmetry model fits the data well in all 
cohorts (all $G^{2}$ s are not significant). This indicates that the data structure is symmetric after accounting for the different distributions of political interest at $T_{1}$ and $T_{2}$ (marginal effects). Hence, the probability of change can be assumed to be equal in both directions and to the same extent. The proportion of youths reporting a drastic increase in political interest (from low to high levels) is virtually the same as those reporting a drastic decrease (from high to low levels). Similarly, the proportion of youths moving from low to medium levels of interest equals the proportion of those moving from medium to low levels, and the same is true for youths moving from medium to high levels and vice-versa. In sum, after accounting for the general increase in political interest, the proportion of youths gaining interest is comparable to the proportion of youths losing interest in all age cohorts.

Finally, we replicated these analyses using the original (5-point) response options and obtained similar results. The quasi-symmetry model fitted the data well in all cohorts. Hence, the analyses on the original response scale supported the results presented above.

\section{Discussion}

In this study, we analyzed stability and change in political interest between the ages of 13 and 28. The findings indicate, first, that the level of political interest was about the same from age 20 to age 28 . This similarity can, potentially, be explained by the stability of political interest on an individual level. We found high individual stability in these ages, and young adults who were low, average, or high on political interest tended to report the same level two years later. In sum, our results show that, by the age of 20 , political interest is as stable as it is during adulthood (cf. Prior 2010; Shani 2009). Second, among the youngest cohorts, all association measures - Pearson $r$, Pearson $r$ corrected for attenuation, Kendall's Tau, and Spearman's $r$ - were substantially higher for the 16-year olds than they were for the 13 year-olds. Indeed, by age 16, the corrected Pearson $r$ was as high as .72. This suggests that political interest starts to stabilize as early as at the age of 16 . This result challenges a 
widely held assumption in the literature on political socialization, i.e. that the period of maximum change in people's political attitudes and skills is between late adolescence and young adulthood. In fact, our result indicates that - as far as interest in politics is concerned the impressionable years are the years of early adolescence, and possibly even before.

In relation to the direction of change, we obtained two interesting results. First, at group level, we observed a general increase in interest in politics, which is much steeper between 16 and 18 years of age than in the 13-15 age range. One interpretation of this finding lies in the ideas that - at these ages - adolescents obtain cognitive abilities that allow abstract thinking and reasoning (Wray-Lake and Syvertsen 2011), and they learn more about society and the wider world. Another possibility is that youths become more interested in political issues because they are approaching voting age, and their "social environment (as parents and teachers) anticipate a 'life event' in becoming an enfranchised voter' (Zeglovits and Zandonella 2013, p. 1087). Even if our results are consistent with both these ideas, it is worth noting that there was no national election in Sweden in 2012 (when we collected data from the 18 year-olds). Hence, cognitive maturation is a more plausible explanation for the increase in political interest that we observed between 16 and 18 years of age.

Second, by controlling for this general pattern of increase, we found - at individual level - that the proportion of youths losing their interest in politics is comparable with the proportion of youths gaining some interest over time. Here, this study brings new insights that have not been reported or been discussed much before. That about as many youths are gaining interest as those who lose interest is in line with the idea that when an individual interest is not yet well established it is susceptible to change, in the direction of either a more stable and higher interest (Hidi and Renninger 2006), or of a decrease in interest. This was especially true for our 13 year-old sample, in which about $25 \%$ of youths increased their level of interest, while a similar proportion, $20 \%$, lost their curiosity about politics two years later. 
The finding indicates that - for better understanding of the factors that influence the development of political interest among youths - we also need to take into account potential obstacles that prevent adolescents from maintaining and cultivating their interest over time. In this regard, we suggest that the traditional models of political socialization (e.g., Amnå 2012; Barrett and Brunton-Smith 2014) could fruitfully be integrated into developmental theories of individual interest (e.g., Hidi and Renninger 2006; Krapp 2005) to explain changes - both increases and decreases - in political interest among youths. For example, Krapp (2005) maintains that the development of an individual interest is determined by the fulfillment of basic needs, such as relatedness, autonomy, and competence (see Deci and Ryan 2000). On this view, a social environment that does not allow youths to satisfy these needs is an obstacle to the development of their interest in politics. Instead, a lack of opportunities to voice ideas and to be listened to (not only by parents, peers, teachers, but also by political figures and institutions) can seriously undermine youths' curiosity about political matters.

Understanding the extent to which youths gain and lose interest in politics over time is especially important for future research on predictors of change. Previous research has shown that political interest is not the exact opposite of political apathy, i.e. a lack of political interest. For example, van Deth and Elff $(2000,2001)$ reported that political apathy shows much greater cross-national variation than political interest and, even more importantly, that socio-demographic characteristics (e.g., gender, age, and education) are differentially associated with political apathy and political interest. As the authors concluded, even when both political interest and apathy are operationalized on the basis of a single indicator, they should be treated separately and not as complements (van Deth and Elff 2000). In sum, the predictors of gaining political interest are not necessarily the same as those of losing it. 
With only two waves of data available for all the cohorts we could not model individual trajectories of political interest over longer periods of time. We were unable to test whether the respondents who lost their interest in politics were likely to remain disinterested in the long run or to revive their curiosity later on. Even if we acknowledge time as a limitation, it is also worth noting that our research design allowed us to cover a wide age range while reducing the risk of the potential confounding influences of mainstream societal or political changes within the country (all data were collected within three years). Related to the research design, we also need to acknowledge that we could not disentangle birth-cohorts from age effects neither could we test if youths of different age responded differently to specific events during the data collections. Even though our cohorts were very close to each other and we have no reasons to believe that birth-cohorts effect influenced our results, we cannot discard the possibility that social or political events might have affected youths' political interest during the time of the data collection.

A second limitation of the study is related to the single item used to measure political interest. It is generally preferable to use composite scales to assess political attitudes, opinions and preferences because they have greater reliability. That is, a response to a single question is more vulnerable to error (van Deth 1989). Nonetheless, we are not aware of any report of the unreliability of the item on political interest. In addition, even though future research would certainly benefit from a more comprehensive assessment of political interest, use of the standard single item allowed us to make comparisons with previous works (e.g., Prior 2010, Shani 2009), which provides for continuity. The possibility of comparing our estimates with those reported in previous studies was an issue of importance to us. In sum, the pros of using this item are equal to (or even exceed) the cons.

Despite its limitations, this study gives some hints about the origins of the development of political interest. Given the crucial role played by political interest in favoring political 
activism and skills, programs aimed at revitalizing curiosity and awareness about politics among politically disinterested youths are fundamental to healthy democracies (Westheimer and Kahne 2004). The possibility of developing such programs rests on our understanding of the factors that boost or reduce political interest and on the age range that should be targeted. Our results clearly indicate that political interest is malleable before 18 years of age, and that the greatest scope for change in political interest is between the ages of 13 and 15. It is during this period that parents, teachers, and role models in general can potentially raise youths' interest in political and societal issues.

During this time of change, adolescents' curiosity about political matters shows ebbs and flows that we need to take into account when planning interventions and guiding young people in civic education. We should not focus exclusively on stimulating disinterested youths, but also nourish interested youths. This is probably more important today than in the past given that the contemporary post-broadcast era is characterized by wide variation in exposure to new media: Just as politically interested citizens have easy access to updated political information, politically disinterested citizens can very easily avoid news exposure (Prior 2007). This is crucial to the generations that have tended to assume new and more expressive styles of political and civic engagement, which are defined around political use of social media (Bennett et al. 2011). For this reason, intervening to sustain youths' interest in politics is a challenging but important task. In this study, we have shown that future efforts with regard to both research and intervention - should be concerned with political interest during early adolescence. 


\section{References}

Achen, C. H. (1975). Mass political attitudes and the survey response. The American Political Science Review, 69(4), 1218-1231.

Agresti, A. (2013). Categorical data analysis (Third Edition). Hoboken, NJ: John Wiley \& Sons.

Alwin, D. F. (1994). Aging, personality and social change: The stability of individual differences over the adult life-span. In D. L. Featherman, R. M. Lerner, \& M. Perlmuter (Eds.), Life-Span Development and Behavior (pp. 135-85). Hillsdale, NJ: Lawrence Erlbaum.

Amnå, E. (2012). How is civic engagement developed over time? Emerging answers from a multidisciplinary field. Journal of Adolescence, 35, 611-627. doi:10.1016/j.adolescence.2012.04.011

ANES (2014). User's Guide and Codebook for the ANES 2012 Time Series Study. Ann Arbor, MI and Palo Alto, CA: the University of Michigan and Stanford University.

Barrett, M. \& Brunton-Smith, I. (2014). Political and civic engagement and participation: Towards an integrative perspective. Journal of Civil Society, 10, 5-28. doi:10.1080/17448689.2013.871911

Bennett, S. E., Flickinger, R. S., \& Rhine, S. L. (2000). Political talk over here, over there, over time. British Journal of Political Science, 30(01), 99-119.

Bennett, W. L., Wells, C., \& Freelon, D. (2011). Communicating civic engagement: contrasting models of citizenship in the youth web sphere. Journal of Communication, 61(5), 835-856.

Berti, A. E. (2005). Children's understanding of politics. In M. Barrett \& E. BuchananBarrow (Eds.), Children's understanding of society (pp. 69-104). Hove, UK: Psychology Press. 
Best, S. J., \& Krueger, B. S. (2005). Analyzing the representativeness of Internet political participation. Political Behavior, 27, 183-216. doi:10.1007/s11109-005-3242-y

Brady, H. E., Verba, S., \& Schlozman, K. L. (1995). Beyond SES: A resource model of political participation. American Political Science Review, 89, 271-294. doi: $10.2307 / 2082425$

Connell, R.W. (1971). The child's construction of politics. Carlton, Aust.: Melbourne University Press.

Craig, S. C., Niemi, R. G., \& Silver, G. E. (1990). Political efficacy and trust: A report on the NES pilot study items. Political Behavior, 12, 289-314. doi:10.1007/BF00992337

Deci, E. L., \& Ryan, R. M. (2000). The "what" and "why" of goal pursuits: Human needs and the self-determination of behavior. Psychological Inquiry, 11, 227-268. doi:10.1207/S15327965PLI1104_01

Delli Carpini, M. X., \& Keeter, S. (1996). What Americans know about politics and why it matters. New Haven, CT: Yale University Press.

Dostie-Goulet, E. (2009). Social networks and the development of political interest. Journal of Youth Studies, 12, 405-421. doi:10.1080/13676260902866512

ESS Round 6: European Social Survey Round 6 Data (2012). Data file edition 2.0. Norwegian Social Science Data Services, Norway: Data Archive and distributor of ESS data.

Eveland, W. P. Jr., \& Scheufele, D. A. (2000). Connecting news media use with gaps in knowledge and participation. Political Communication, 17, 215-237. doi:10.1080/105846000414250

Glenn, N. D., \& Grimes, M. (1968). Aging, voting, and political interest. American Sociological Review, 33(04), 563-575. 
Hertzog, C., \& Nesselroade, J. R. (2003). Assessing psychological change in adulthood: an overview of methodological issues. Psychology and Aging, 18, 639. doi:10.1037/08827974.18.4.639

Hidi, S., \& Renninger, K. A. (2006). The four-phase model of interest development. Educational Psychologist, 41, 111-127. doi:10.1207/s15326985ep4102_4

Hooghe, M., \& Dejaeghere, Y. (2007). Does the 'monitorial citizen' exist? An empirical investigation into the occurrence of postmodern forms of citizenship in the Nordic countries. Scandinavian Political Studies, 30(2), 249-271.

Hooghe, M., \& Wilkenfeld, B. (2008). The stability of political attitudes and behaviors across adolescence and early adulthood: A comparison of survey data on adolescents and young adults in eight countries. Journal of Youth and Adolescence, 37, 155-167. doi:10.1007/s10964-007-9199-x

Jennings, M. K., \& Markus, G. B. (1984). Partisan orientations over the long haul: Results from the three-wave Political Socialization Panel Study. American Political Science Review, 78, 1000-18.

Jennings, M. K., \& Niemi, R. G. (1974). The political character of adolescence. Princeton, NJ: Princeton University Press.

Jennings, M. K., \& Niemi, R. G. (1981). Generations and politics: A panel study of young adults and their parents. Princeton, NJ: Princeton University Press.

Kinder, D. R., \& Sears, D. O. (1985). Public opinion and political action. In G. Lindzey \& E. Aronson (Eds.), The Handbook of Social Psychology, $3^{\text {rd }}$ ed. Vol. 2 (pp. 659-741). New York: Random House.

Krapp, A. (2005). Basic needs and the development of interest and intrinsic motivational orientations. Learning and Instruction, 12, 383-409. doi:10.1016/j.learninstruc.2005.07.007 
Krapp, A. (2007). An educational-psychological conceptualization of interest. International Journal for Educational and Vocational Guidance, 7, 5-21. doi:10.1007/s10775-0079113-9

Krosnick, J. A., \& Alwin, D. F. (1989). Aging and susceptibility to attitude change. Journal of Personality and Social Psychology, 57, 416-425. doi:10.1037/0022-3514.57.3.416

Madsen, D. (2004). Stability coefficient. In M. S. Lewis-Beck, A. Bryman, \& T. Futing Liao (Eds.), The SAGE Encyclopedia of Social Science Research Methods (pp. 1064-1065). Thousand Oaks, CA: Sage Publications, Inc.

McArdle, J. J., \& Nesselroade, J. R. (1994). Structuring data to study development and change. In S. H. Cohen \& H. W. Reese (Eds.), Life-span developmental psychology: Methodological innovations (pp. 223-268). Hillsdale, NJ: Erlbaum.

Neundorf, A., Smets, K., \& García-Albacete, G. M. (2013). Homemade citizens: The development of political interest during adolescence and young adulthood. Acta Politica, 48, 92-116. doi:10.1057/ap.2012.23

Prior, M. (2007). Post-broadcast democracy: How media choice increases inequality in political involvement and polarizes elections. New York, NY: Cambridge University Press.

Prior, M. (2010). You've either got it or you don't? The stability of political interest over the life cycle. The Journal of Politics, 72, 747-766. doi:10.1017/S0022381610000149

Sears, D. O. (1983). The persistence of early political predispositions: The roles of attitude object and life stage. Review of Personality and Social Psychology, 4(1), 79-116.

Shani, D. (2009). On the origins of political interest. Ph.D. dissertation, Princeton University. Silvia, P. J. (2008). Interest--The Curious Emotion. Current Directions in Psychological Science, 17, 57-60. doi:10.1111/j.1467-8721.2008.00548.x 
Strömbäck, J., \& Shehata, A. (2010). Media malaise or a virtuous circle? Exploring the causal relationships between news media exposure, political news attention and political interest. European Journal of Political Research, 49, 575-597. doi:10.1111/j.1475-6765.2009.01913.x

van Deth, J. W. (1989). Interest in politics. In M. K. Jennings \& J. W. van Deth, (Eds.), Continuities in political action: A longitudinal study of political orientations in three western democracies, (pp. 275-312). Berlin: de Gruyter.

van Deth, J. W., Abendschön, S., \& Vollmar, M. (2011). Children and Politics: An Empirical Reassessment of Early Political Socialization. Political Psychology, 32, 147-174. doi:10.1111/j.1467-9221.2010.00798.x

van Deth, J., \& Elff, M. (2000). Political Involvement and Apathy in Europe 1973-1998. Working paper, Mannheimer Zentrum für Europäische Sozialforschung, 33. van Deth, J., \& Elff, M. (2001). Politicisation and Political Interest in Europe: A Multi-Level Approach. Working paper, Mannheimer Zentrum für Europäische Sozialforschung, 36. Verba, S., Schlozman, K. L., \& Brady, H. E. (1995). Voice and equality: Civic voluntarism in American politics. Cambridge, MA: Harvard University Press.

von Eye, A., \& Mun, E. Y. (2013). Log-linear modeling: Concepts, interpretation, and application. New York, NY: Wiley.

von Eye, A., Bogat, A., \& Rhodes, J. (2006). Variable-oriented and person-oriented perspectives of analysis: The example of alcohol consumption in adolescence. Journal of Adolescence, 29, 981-1004. doi:10.1016/j.adolescence.2006.06.007

Westheimer, J., \& Kahne, J. (2004). What kind of citizen? The politics of educating for democracy. American Educational Research Journal, 41, 237-269.

doi:10.3102/00028312041002237 
Wiley, D. E., \& Wiley, J. A. (1970). The estimation of measurement error in panel data. American Sociological Review, 35(1), 112-117.

Wray-Lake, L., \& Syvertsen, A. K. (2011). The developmental roots of social responsibility in childhood and adolescence. In C. A. Flanagan \& B. D. Christens (Eds.), Youth civic development: Work at the cutting edge. New Directions for Child and Adolescent Development, 134, 11-25.

Zeglovits, E., \& Zandonella, M. (2013). Political interest of adolescents before and after lowering the voting age: the case of Austria. Journal of Youth Studies, 16, 1084-1104. doi:10.1080/13676261.2013.793785 
Figure 1. Means of political interest by age

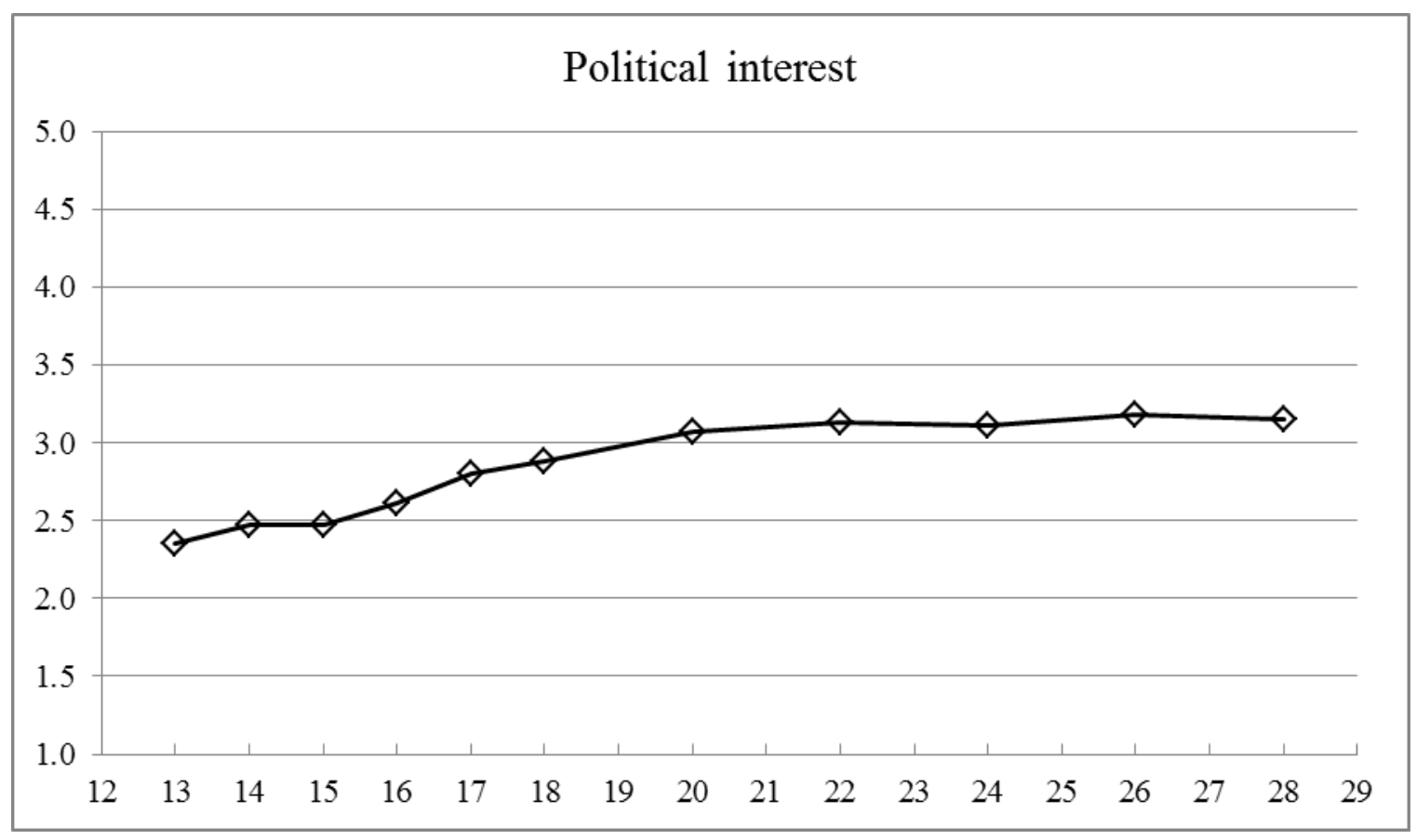


Table 1. Correlations of political interest over the two-year time span and the percentage of youths providing the same response or moving by no more than one response category over the two years

\begin{tabular}{lcccccc}
\hline & Ages 13-15 & Ages 16-18 & Ages 20-22 & Ages 22-24 & Ages 26-28 & Mean \\
\hline Pearson's $r$ & .354 & .597 & .649 & .656 & .704 & .591 \\
Corrected $r$ & .473 & .717 & .780 & .788 & .846 & .721 \\
Kendall's Tau-b $r_{\tau}$ & .306 & .517 & .599 & .578 & .669 & .529 \\
Spearman's $r_{s}$ & .355 & .599 & .664 & .635 & .730 & .600 \\
Identical scores & 39.3 & 44.8 & 55.3 & 55.2 & 63.8 & 50.2 \\
Identical plus +/-1 point & 78.2 & 83.4 & 93.5 & 94.8 & 95.5 & 87.8 \\
\hline
\end{tabular}

Note. All correlations are significant at $p<.001$. 
Table 2. Latent change models for political interest

\begin{tabular}{lllll}
\hline Cohort & Mean intercept & Mean slope & Variance intercept & Variance slope \\
\hline 13 to 15 years & $2.334(0.042)^{* * *}$ & $0.122(0.048)^{*}$ & $1.209(0.055)^{* * *}$ & $1.556(0.096)^{* * *}$ \\
16 to 18 years & $2.654(0.049)^{* * *}$ & $0.272(0.043)^{* * *}$ & $1.429(0.059)^{* * *}$ & $1.097(0.068)^{* * *}$ \\
20 to 22 years & $3.097(0.048)^{* * *}$ & $-0.060(0.040) \mathrm{ns}$ & $1.051(0.064)^{* * *}$ & $0.728(0.070)^{* * *}$ \\
22 to 24 years & $3.239(0.047)^{* * *}$ & $-0.039(0.040) \mathrm{ns}$ & $0.881(0.064)^{* * *}$ & $0.639(0.056)^{* * *}$ \\
26 to 28 years & $3.207(0.043)^{* * *}$ & $-0.064(0.033) \mathrm{ns}$ & $0.880(0.057)^{* * *}$ & $0.525(0.050)^{* * * *}$ \\
\hline
\end{tabular}

Note. Entries are unstandardized coefficients (standard errors in parentheses). $* * * p<.001, * p<.05$. 
Table 3. Turnover tables for political interest with goodness-of-fit statistic likelihood ratios $\left(G^{2}\right)$ for the log-linear models

\begin{tabular}{|c|c|c|c|c|c|c|c|c|c|c|c|c|c|c|c|}
\hline & \multicolumn{3}{|c|}{ Ages 13 to 15} & \multicolumn{3}{|c|}{ Ages 16 to 18} & \multicolumn{3}{|c|}{ Ages 20 to 22} & \multicolumn{3}{|c|}{ Ages 22 to 24} & \multicolumn{3}{|c|}{ Ages 26 to 28} \\
\hline \multirow[b]{2}{*}{$\mathrm{T}_{1} \backslash \mathrm{T}_{2}$} & \multicolumn{3}{|c|}{ Mediu } & \multicolumn{3}{|c|}{ Mediu } & \multicolumn{3}{|c|}{ Mediu } & \multicolumn{3}{|c|}{ Mediu } & \multicolumn{3}{|c|}{ Mediu } \\
\hline & Low & $\mathrm{m}$ & High & Low & $\mathrm{m}$ & High & Low & $\mathrm{m}$ & High & Low & $\mathrm{m}$ & High & Low & $\mathrm{m}$ & High \\
\hline \multirow{2}{*}{ Low } & 33.5 & 15.7 & 5.5 & 24.7 & 14.5 & 5.6 & 15.3 & 7.1 & 1.3 & 10.8 & 4.7 & 1.5 & 12.6 & 6.0 & 0.9 \\
\hline & $(61.3)$ & $(28.6)$ & $(10.1)$ & $(55.1)$ & $(32.5)$ & $(12.5)$ & $(64.5)$ & $(30.0)$ & $(5.5)$ & $(63.8)$ & $(27.5)$ & $(8.7)$ & $(64.8)$ & $(30.8)$ & (4.4) \\
\hline \multirow{2}{*}{ Medium } & 11.5 & 14.2 & 5.7 & 6.8 & 14.2 & 7.8 & 9.9 & 24.1 & 7.7 & 7.1 & 25.1 & 10.1 & 7.7 & 28.4 & 4.9 \\
\hline & $(36.1)$ & $(44.7)$ & $(19.2)$ & (23.5) & $(49.4)$ & $(27.1)$ & (23.7) & $(57.7)$ & (18.6) & (16.9) & $(59.3)$ & $(23.8)$ & $(18.8)$ & $(69.3)$ & (12.0) \\
\hline \multirow{2}{*}{ High } & 3.5 & 4.4 & 5.7 & 0.8 & 5.2 & 20.4 & 0.6 & 8.8 & 25.2 & 0.7 & 11.1 & 28.8 & 0.6 & 8.1 & 30.9 \\
\hline & $(25.8)$ & $(32.3)$ & (41.9) & $(3.2)$ & $(19.7)$ & $(77.1)$ & (1.9) & $(25.5)$ & $(72.7)$ & $(1.8)$ & $(27.3)$ & $(70.9)$ & $(1.6)$ & $(20.4)$ & $(78.0)$ \\
\hline \multicolumn{16}{|l|}{$G^{2}$ Quasi- } \\
\hline symmetry & & \multicolumn{2}{|c|}{$.24(1) \mathrm{ns}$} & \multicolumn{3}{|c|}{$1.79(1) \mathrm{ns}$} & \multicolumn{3}{|c|}{$2.34(1) \mathrm{ns}$} & \multicolumn{3}{|c|}{$2.44(1) \mathrm{ns}$} & \multicolumn{3}{|c|}{$1.53(1) \mathrm{ns}$} \\
\hline
\end{tabular}

Note. Numbers in the upper half of the table are percentages (row percentages in parentheses); in the lower half, degrees of freedom are in parentheses. $* * * p<.001, * p<.05$ 